\title{
Diversity, Inclusion, and Context in Asian Higher Education
}

\section{Catherine Shea Sanger}

Diversity in the classroom is a valuable opportunity to enrich student learning. Significant trends impacting the Asian higher education environment are creating new prospects and imperatives to harness diversity for learning. ${ }^{l}$ Student and faculty mobility continues apace. New institutions of higher education are being forged through international

${ }^{1}$ Sun Hee Kim Gertz, Betsy Huang, and Lauren Cyr, eds., Diversity and Inclusion in Higher Education and Societal Contexts: International and Interdisciplinary Approaches (New York: Palgrave Macmillan, 2018); Paloma Castro, Jane Woodin, Ulla Lundgren, and Michael Byram, "Student Mobility and Internationalisation in Higher Education: Perspectives from Practitioners," Language and Intercultural Communication 16, no. 3 (2016): 418-436; Peter D. Hershock, "Equity and Higher Education in the Asia-Pacific," in The Palgrave Handbook of Asia Pacific Higher Education, edited by C. Collins, M. Lee, J. Hawkins, and D. Neubauer (New York: Palgrave Macmillan, 2016), 331-344.

\section{S. Sanger $(\bowtie)$}

Yale-NUS College, Singapore, Singapore

e-mail: catherine.sanger@yale-nus.edu.sg

(C) The Author(s) 2020

C. S. Sanger and N. W. Gleason (eds.),

Diversity and Inclusion in Global Higher Education, https://doi.org/10.1007/978-981-15-1628-3_1 
and intra-regional partnerships, while older institutions are experimenting with innovative pedagogies. At the same time, instructors and education scholars are moving past limiting cultural assumptions and false dichotomies of "Asian" and "Western" to understand and support students' full learning potential. As a result, faculty are teaching more diverse students in more diverse formats. For all these reasons, it is an important moment to center diversity and inclusion in Asian higher education institutions.

The literature on diversity in higher education has created a substantial foundation for many of the contributions in this volume, but it also has some important limitations. First, too often the existing literature frames student diversity as a challenge to be overcome for faculty teaching, rather than an opportunity to advance student learning. Second, much of the literature drawn from the North American educational context uses "diversity" as code for "race." This literature is therefore often less holistic in its approach to inclusive pedagogy and curricular design that it could be. It makes sense that US-focused literature is highly attentive to the intersections of race, socio-economic status, and educational background that are specific to the American context. However, the result is that lessons do not always travel well to other settings. Lastly, and most importantly for this volume, diversity and inclusion literature is often not very connected or attentive to Asia, a region where higher education institutions and opportunities are expanding and diversifying in hugely exciting and important ways.

The contributions in this volume reflect and build on these observations, synthesizing international research, best practice literature, and greater responsiveness to the local context. Together the authors explore different dimensions of diversity and inclusion across varied higher education environments.

This introductory chapter sets the scene for the larger volume, explaining how diversity enhances learning for all students when matched with proactive inclusion in the classroom and curriculum. First, it highlights regional and global trends that are increasing attention to diversity across Asian higher education contexts. The chapter then considers the distinction between diversity and inclusion, and how that distinction is salient for pedagogy and curriculum design. It concludes with an overview of the goals and contents of the book. 


\section{Diversity and Inclusion in Asian Higher Education ConTEXTS}

Diversity means variety and range, a significant degree of variation within a particular group or community across a range of characteristics. In educational settings, diversity often connotes the bringing together of individuals with differences, and sometimes unexpected similarities. Diversity involves all aspects of identity and experience, including nationality, ethnicity, language, gender, sexuality, value system, socio-economic context, family structure, age, ability, educational background, and learning styles. Diversity is also found in the personalities, backgrounds, and teaching approaches of individual faculty members. Some classrooms are more diverse than others, but all classrooms are diverse in ways that can enhance learning if properly harnessed. Students stand to learn more when they feel secure sharing their different perspectives and identities with each other. Attention to diversity is also important as we prepare future graduates for a changing world. Diversity in pedagogy, curricula, and student identities helps enable critical thinking, communication, and problemsolving competencies required to impart impactful learning for presentday students. For all these reasons, and especially when teaching in very diverse contexts, it is important to proactively anticipate and deliberately incorporate students' different backgrounds and strengths into pedagogy and course design.

This volume uses the term "Asia" in its title to highlight shared concerns and considerations that are particularly relevant in many Asian higher education contexts. That said, this book is not an encyclopedic account. Asia is a geographic domain with a multitude of cultures, subcultures, political systems, social institutions, and educational contexts. We have not attempted to "cover" all the countries in the region. Most of the chapters in the volume, to the extent that they focus on a particular geographic-political area, focus on Northeast, Southeast, and South Asia. Institutions and higher education trends in North Asia, the Caucuses, Central Asia, and the Middle East do not feature prominently in this volume.

Additionally, a novel contribution of this book is that it speaks to the challenges and opportunities facing internationally minded institutions of higher education. All of the institutions that serve as case studies in this volume have one or more of the following traits: they were forged 
through formal international partnerships, they broadly emphasize international engagement, they have highly multi-national faculties, and/or they enroll significant numbers of international students. Most chapters in this volume describe and draw lessons from institutions that are distinctive, competitive, innovative, and often new to their given context. Several chapters present case studies of institutions that have been operating for roughly a decade or less, including Yale-NUS College, Ashoka University, Asian Women's University (AUW), University of Reading Malaysia, and Singapore University of Social Sciences (SUSS). At the same time, the volume has contributors from very established, older institutions including the National University of Singapore, which is consistently ranked as one of the very best universities in the Asia Pacific region. Several chapters highlight interdisciplinary programs and liberal arts institutions (e.g. Yale-NUS, Ashoka, AUW, and Tokyo Christian University), while others draw case studies from pre-professional and discipline-specific institutions (University of Reading Malaysia, SUSS). Together, the chapters signal that diversity is as important for established as for newer institutions, and for broad and more specific curricular programs alike.

Of course it would be wonderful to have a broader representation of institutional and national contexts from across Asia in the book. However, geographic coverage is not the primary aim here. To take that approach would be to perpetuate the oversimplification that there is one Indian, one Chinese, one South Korean, or one Indonesian higher education context. Moreover, enrolment in higher education among university-age students varies considerably across Asia, so that the very topics explored here will be of more or less relevance to different enclaves within and across countries. $^{2}$ In this sense, the volume brings together case studies from widely different settings, and some themes that will emerge will be as relevant for non-Asian contexts as for many environments in Asia. Nonetheless, although "Asia" (and even eastern Asia and southern Asia) is a broad and somewhat amorphous term, we think it is still worthwhile to dedicate attention to Asian higher education. It represents proximate geographic and in some cases cultural communities and those working in higher education in the region are likely to share some common opportunities, constraints, and influences.

\footnotetext{
${ }^{2}$ Max Roser and Esteban Ortiz-Ospina, "Tertiary Education," https://ourworldindata. org/tertiary-education.
} 
Four trends of particular relevance for discussions of diversity in eastern and southern Asia are described below and include student and faculty mobility; educational experimentation, international partnerships, and branch campuses; socio-economic transformation; and more complex and nuanced understandings of diversity in popular and scholarly discourse. Together, these trends are opening up new possibilities for inclusive pedagogy and institutional leadership in the higher education sphere.

\section{Intra-Regional and International Mobility}

Within Asia, increasing levels of intra-regional mobility by students lead to diverse classrooms in terms of nationality, culture, religion, and prior learning environment. As students move across education systems and cultural contexts, new opportunities to learn from each others' differences emerge, as do unanticipated sources of conflict and alienation. ${ }^{3}$ Further, the tremendous flow of students from Asia to colleges and universities in North America, Australasia, Europe, and beyond makes it important for educators and administrators worldwide to have a more nuanced

\footnotetext{
${ }^{3}$ Thu T. Do and Duy N. Pham, "Challenges of Student Mobility in Southeast Asia," International Higher Education, no. 84 (2016): 24-26; Jenny Lee, Jae-Eun Jon, and Kiyong Byun, "Neo-Racism and Neo-Nationalism Within East Asia: The Experiences of International Students in South Korea," Journal of Studies in International Education 21, no. 2 (2017): 136-155; Peter Kell and Gillian Vogl, eds., Global Student Mobility in the Asia Pacific: Mobility, Migration, Security and Wellbeing of International Students (Cambridge: Cambridge Scholars Publishing, 2010); Die Wen and Jie Hao Hu, "International Students' Experiences in China: Does the Planned Reverse Mobility Work?," International Journal of Educational Development 61 (2018): 204-212; Shin Gi-Wook, Oh Yeon-Cheon, and Rennie J. Moon, eds., Internationalizing Higher Education in Korea: Challenges and Opportunities in Comparative Perspective (New York: Brookings Institution Press, 2016); Ken Lau and Chia-Yen Lin, "Internationalization of Higher Education and Language Policy: The Case of a Bilingual University in Taiwan," Higher Education 74, no. 3 (2017): 437-454; Chan Sheng-Ju, "Shifting Patterns of Student Mobility in Asia," Higher Education Policy 25, no. 2 (2012): 207-224; Miki Horie, "Internationalization of Japanese Universities: Learning from the CAMPUS Asia Experience," International Higher Education 78 (2014): 19-21; Kazuo Kuroda, "Regionalization of Higher Education in Asia," in The Palgrave Handbook of Asia Pacific Higher Education, 141-156; Jane Knight, "Regionalization of Higher Education in Asia: Functional, Organizational, and Political Approaches," in The Palgrave Handbook of Asia Pacific Higher Education, 113-127; Peidong Yang, "Compromise and Complicity in International Student Mobility: The Ethnographic Case of Indian Medical Students at a Chinese University," Discourse: Studies in the Cultural Politics of Education 39, no. 5 (2018): 694-708.
} 
understanding of Asian students' backgrounds and prior educational contexts. Alongside student mobility, we see a great deal of faculty mobility within Asian universities. Student and faculty mobility together creates a greater need to cultivate appreciation for diversity in the classroom. Gaps in understanding arise not only when foreign faculty are brought to new countries to teach but also when professors teaching in their homeland have increasingly diverse students in their classrooms. Faculty are not always intuitively familiar with the educational background and expectations of their students. This, in turn, can diminish teaching effectiveness and serve as a barrier to learning. ${ }^{4}$

\section{International Partnerships, Branch Campuses, and Pedagogical Innovation}

One reason we see so much international faculty mobility is the uptick in international partnerships. The establishment of campuses between Asian universities and institutions of higher education from other parts of the region and world has been a notable feature of the contemporary higher education landscape. Some examples in eastern and southern

\footnotetext{
${ }^{4}$ Louise Morley, Nafsika Alexiadou, Stela Garaz, José González-Monteagudo, and Marius Taba, "Internationalisation and Migrant Academics: The Hidden Narratives of Mobility," Higher Education 76, no. 3 (2018): 537-554; Rajika Bhandari and Alessia Lefébure, eds., Asia: The Next Higher Education Superpower? (New York: Institute of International Education, 2015); Stephanie K. Kim, "Western Faculty 'Flight Risk' at a Korean University and the Complexities of Internationalisation in Asian Higher Education," Comparative Education 52, no. 1 (2016): 78-90; Sauwakon Ratanawijitrasin, "The Evolving Landscape of South-East Asian Higher Education and the Challenges of Governance," in The European Higher Education Area, edited by Adrian Curaj, Liviu Matei, Remus Pricopie, Jamil Salmi, and Peter Scott (New York: Springer, 2015), 221-238; Philip G. Altbach and Maria Yudkevich, "Twenty-First Century Mobility: The Role of International Faculty," International Higher Education 90 (2017): 8-10; Futao Huang, Martin J. Finkelstein, and Michele Rostan, eds., The Internationalization of the Academy: Changes, Realities and Prospects (Dordrecht: Springer, 2014); Terri Kim, "Shifting Patterns of Transnational Academic Mobility: A Comparative and Historical Approach," Comparative Study 45, no. 3 (2009): 387-403; Maria Yudkevich, Philip G. Altbach, and Laura E. Rumbley, eds., International Faculty in Higher Education: Comparative Perspectives on Recruitment, Integration, and Impact (New York: Routledge, 2017); Futao Huang, "International Faculty at Japanese Universities: Their Demographic Characteristics and Work Roles," Asia Pacific Education Review 19, no. 2 (2018): 263-272; Akiyoshi Yonezawa, Hugo Horta, and Aki Osawa, "Mobility, Formation and Development of the Academic Profession in Science, Technology, Engineering and Mathematics in East and South East Asia," Comparative Education 52, no. 1 (2016), 44-61.
} 
Asia include Yale-NUS College, NYU-Shanghai, Duke-Kunshan, Monash University Malaysia, Xi'an Jiaotong-Liverpool University, University of Reading Malaysia, James Cook University in Singapore, the Savannah College of Art and Design in Hong Kong, and Fulbright University Vietnam. In the Persian Gulf region, there has also been a surge of international partnerships over the past decade with universities from Philippines, Australia, India, Canada, the US, the UK, France, Germany, and elsewhere, establishing branch campuses in Education City Qatar, Abu Dhabi, and elsewhere. ${ }^{5}$ These partnerships often bring in foreign-educated faculty and administrators to help these new institutions get established. A lack of understanding of local educational contexts and students' identities can impede the success of these new institutions.

Additionally, many of these partnership programs emphasize curricula and pedagogies that are novel in their local contexts. At the same time, established institutions at the tertiary and secondary level are experimenting with new pedagogies, integrating liberal arts curricular requirements as well as active learning and experimental pedagogies that are sometimes described as more "Western" approaches. Understanding of local educational context can help ensure that students-and their parents-recognize the intended value of these curricular and pedagogical approaches.

\section{Globalization and Economic Transformation}

Students are leaving university and entering into increasingly globalized professional and personal contexts. Learning to excel in a diverse undergraduate setting prepares students to thrive in their postgraduate plans and fosters the resilience necessary for success. At the same time, due to rapid economic development and transformation in the education sector of many Asian nations, students are now attending universities that are radically different from what their parents may have experienced. The rate of change is so high that students may also be receiving an education that is very different from what they themselves were prepared for in primary and secondary school. This can lead students to feel ill-equipped and isolated once in university and to underperform academically as a result.

${ }^{5}$ Michael Lanford and William G. Tierney, "The International Branch Campus: Cloistered Community or Agent of Social Change?," in The Palgrave Handbook of Asia Pacific Higher Education, 157-172; Bhandari and Lefébure, Asia. 
As my co-editor Nancy Gleason has argued elsewhere, the goals of contemporary higher education need to involve developing students' habits of mind, to question what is already known, and to learn how to learn across seemingly separate disciplines and contexts. ${ }^{6}$ In this age of automation, climate change, and significant demographic shifts, higher education graduates need to be adaptive to new environments and be able to utilize knowledge from one situation in another. Simple information transfer no longer constitutes adequate advanced education and has become instead a necessary first step. Students need to know how to apply - and adapt - the knowledge they possess in ever-changing situations. These forces combine to elevate the importance of intercultural learning and active inclusion efforts in many Asian higher education contexts, both to ensure students get the most gain from their education, and to help students apply that education and thrive in times of tremendous change. ${ }^{7}$

\section{Moving Toward More Complex Understandings of Diversity}

Together, these trends call to the fore more complex understandings of diversity and highlight the importance of centering diversity and inclusion efforts in Asian universities, especially those that have experienced significant shifts in student and faculty demographics, pedagogies, or curriculum.

${ }^{6}$ Nancy W. Gleason, ed., "Introduction" and "Singapore's Higher Education Systems in The Era of the Fourth Industrial Revolution: Preparing Lifelong Learners," in Higher Education in the Era of the Fourth Industrial Revolution (Singapore: Palgrave Macmillan, 2018), 1-11, 145-169.

${ }^{7}$ Mark Heyward, "From International to Intercultural: Redefining the International School for a Globalized World," Journal of Research in International Education 1, no. 1 (2002): 9-32; Gundula G. Hiller and Maja Wozniak, "Developing an Intercultural Competence Programme at an International Cross-Border University," Intercultural Education 20, no. 4 (2009): 113-124; Leda Kamenopoulou, ed., Inclusive Education and Disability in the Global South (New York: Palgrave, 2018); Miki Sugimura, "Transformation of Higher Education Systems in the Dynamics of Contemporary Globalization: The Case of Japan," in The Palgrave Handbook of Asia Pacific Higher Education, 183-193; Christopher Ziguras, "Globalization and the Transformation of Asian Higher Education," in The Palgrave Handbook of Asia Pacific Higher Education, 73-88; Deanne E. Neubauer and John Hawkins, "Prospects for Higher Education in the Midst of Globalization," in The Palgrave Handbook of Asia Pacific Higher Education, 57-72. 
One sometimes hears or reads in popular discourse that Chinese or Asian students - and these two terms are unfortunately often conflatedare only trained to engage in rote-learning, memorization, and regurgitation. Asian students are often stereotyped as having been trained since birth to be deferential to authority and parrot back to teachers, and as a result struggle when asked to engage with critical thinking or active learning. Though it is true that some education systems and institutions emphasize deference and memorization, we need to move past such oversimplified generalizations. Many of us teaching and researching education in institutions across Asia observe that contemporary students are exposed to a much more varied set of pedagogies and can absolutely thrive when asked to engage in active and complex learning. ${ }^{8}$ There is a growing body of literature demonstrating that "Asian" students cannot be lumped together as a learning type and that Asian students are not uniformly different in their learning preferences, motivations, and habits than American, European, or Australian students. More recent and more nuanced literature on the interaction between national origin, culture, and learning is helping scholars and practitioners move past cultural essentialism and narrow assumptions about "Asian learning styles" that dominated the literature in the past. ${ }^{9}$ There is no single Eastern and no single Western learner type, and supposed differences in learning styles between groups

\footnotetext{
${ }^{8}$ For more nuanced and critical studies of the ways country and culture of origin may impact learning see Megan Watkins, Christina Ho, and Rose Butler, "Asian Migration and Education Cultures in the Anglo-Sphere," Journal of Ethnic and Migration Studies 43, no. 14 (2017): 2283-2299; AKM Ahsan Ullah and Muhammad Azizuddin, "South Asian Student Migration to Nordic Countries: Changing Initial Motivations," Asian Profile 46, no. 1 (2018); Rahul Choudaha, "Three Waves of International Student Mobility (1999-2020)," Studies in Higher Education 42, no. 5 (2017): 825-832; Choy Siew Chee, Daljeet Singh, Yow Lin Liew, Mun Yee Lee, Audrey Malenee, and Norkhadirah Anuar, "Influence of Culture on Students' Awareness of How and Why They Learn," Malaysian Journal of Learning and Instruction 12 (2015): 49-67; Joseph Kee-Kuok Wong, "Are the Learning Styles of Asian International Students Culturally or Contextually Based?," International Education Journal 4, no. 4 (2004): 154-166; David Kember, "Why Do Chinese Students Out-Perform Those from the West? Do Approaches to Learning Contribute to the Explanation?," Cogent Education 3, no. 1 (2016): 1248187; David Kember, "Misconceptions About the Learning Approaches, Motivation and Study Practices of Asian Students." Higher Education 40, no. I (2000): 99-121.

${ }^{9}$ E. Sadler-Smith and F. Tsang, "A Comparative Study of Approaches to Studying in Hong Kong and the United Kingdom," British Journal of Educational Psychology 68, no. 1 (1998): 81-93; Doris Y. P. Leung, Paul Ginns, and David Kember, "Examining the Cultural Specificity of Approaches to Learning in Universities in Hong Kong and Sydney,"
} 
are still very much up for debate. ${ }^{10}$ Even in studies that argue culture or national origin play a role in shaping how students learn, individual agency and adaptability are also shown to be important inputs. ${ }^{11}$

Recent scholarship of teaching and learning in international contexts also highlights the important recognition that diversity is more than race, nationality, and religion. Even in seemingly heterogeneous learning environments where all students share a common ethnicity or citizenship, new research shows that greater awareness of students' manifold differences can enhance teaching effectiveness. ${ }^{12}$ The forms of diversity that

Journal of Cross-Cultural Psychology 39, no. 3 (2008): 251-266; Chang Zhu, Martin Valcke, and Tammy Schellens, "A Cross-Cultural Study of Chinese and Flemish University Students: Do They Differ in Learning Conceptions and Approaches to Learning?," Learning and Individual Differences 18, no. 1 (2008): 120-127; F. Sushila Niles, "Cultural Differences in Learning Motivation and Learning Strategies: A Comparison of Overseas and Australian Students at an Australian University," International Journal of Intercultural Relations 19, no. 3 (1995): 369-385; Prem Ramburuth and John McCormick, "Learning Diversity in Higher Education: A Comparative Study of Asian International and Australian Students," Higher Education 42, no. 3 (2001): 333-350; Haoda Sun and John E. Richardson, "Perceptions of Quality and Approaches to Studying in Higher Education: A Comparative Study of Chinese and British Postgraduate Students at Six British Business Schools," Higher Education 63, no. 3 (2012): 299-316; David Kember, "International Students from Asia," in The Routledge International Handbook of Higher Education, edited by Malcom Tight, Ka Ho Mok, Jeroen Huisman, and Christopher Morphew (Florence: Routledge, 2009), 47-60.

${ }^{10}$ Some studies do find salient differences in the learning approaches or preferences of students according to country of origin, but often at modest degrees. Yusuke Sakurai, Anna Parpala, Kirsi Pyhältö, and Sari Lindblom-Ylänne, "Engagement in Learning: A Comparison Between Asian and European International University Students," Compare: A Journal of Comparative and International Education 46, no. 1 (2016): 24-47; Yusuke Sakurai, Kirsi Pyhältö, and Sari Lindblom-Ylänne, “Are Chinese University Students More Likely to Exhibit a Surface Approach to Learning Than Other International Students in Finland?," Journal of Research in International Education 13, no. 2 (2014): 135-148; Teklu Abate Bekele, "Context in Comparative and International Education Studies," in Annual Review of Comparative and International Education 2017 (International Perspectives on Education and Society, Vol. 34), edited by A. Wiseman (Bingley: Emerald Publishing Limited, 2018), 275-299; Chunyan Yang and Li Bai, "The Use of Metacognitive Strategies by Chinese Phd Students of Social Sciences in Australian Universities," International Journal of Educational Research 97 (2019): 43-52.

${ }^{11}$ Sakurai, Parpala, Pyhältö, and Lindblom-Ylänne, "Engagement in Learning"; Swee Noi Smith, "Approaches to Study of Three Chinese National Groups," British Journal of Educational Psychology 71, no. 3 (2001): 429-441.

12 W. James Jacob and Weiyan Xiong, "Higher Education Capacity for What? Balancing Issues of Equity, Efficiency, Choice, and Excellence," in The Palgrave Handbook of Asia Pacific Higher Education, 345-363; M. N. N. Lee, "Regional Trends in Asian Higher 
are salient for educators to consider will vary across contexts because Asia is a very diverse place. Inclusion in a highly multi-ethnic, multi-religious environment like Singapore will probably look different than in an ethnically and religiously more homogeneous country like Cambodia. In some university contexts within India or China, heterogeneity of language and dialect will be of primary importance. In other contexts, such as many Japanese universities, linguistic diversity may not feature as prominently, but socio-economic diversity could be very important for students' learning experience. Moreover, and very importantly, not all students from the same country or educational context learn in the same ways. ${ }^{13}$ Within the same country, some students may have attended streamed schools where they only studied math and science for several years, whereas others may have attended International Baccalaureate schools and studied a range of subjects simultaneously. Some students may be accustomed to small classes and active learning methods, whereas others come from institutions that emphasized memorization and relatively passive learning. Students are also not stagnant and without agency. They bring certain cultural expectations and practices with them to university, but those change and are molded by new contexts with time. ${ }^{14}$

Together, these trends and shifting understandings of the higher education landscape have brought diversity into the foreground of teaching and learning discourse. It would be a mistake, however, to strive for student diversity, and then stop. Diversity facilitates powerful learning, but to be fully realized needs to be matched with intentional strategies of inclusion. This conviction underpins much of the edited volume.

\section{How Diversity With Inclusion Promotes Learning}

Some classrooms are visibly and audibly very diverse, with students of different nationalities, ethnic groups, ages, gender identities, and languages.

Education," in The Palgrave Handbook of Asia Pacific Higher Education, 129-139; Cora Lingling Xu, "Identity and Cross-Border Student Mobility: The Mainland China-Hong Kong Experience," European Educational Research Journal 14, no. 1 (2015): 65-73.

${ }^{13}$ Qi Wu, "Re-examining the 'Chinese Learner': A Case Study of Mainland Chinese Students' Learning Experiences at British Universities," Higher Education 70, no. 4 (2015): 753-766.

${ }^{14}$ Tang T. Heng, "Different Is Not Deficient: Contradicting Stereotypes of Chinese International Students in US Higher Education," Studies in Higher Education 43, no. 1 (2018): 22-36. 
But almost every classroom has important varieties of diversity that can amplify learning when recognized, and hinder learning when overlooked. For example, variation in prior educational experience is not easily seen, but nonetheless significant. When instructors recognize that their students come from different economic and educational contexts, they can use that diversity to expand the perspectives and learning that occurs in class. When instructors fail to recognize this form of diversity they can do unintentional harm to student learning.

Diversity among students and faculty deepens learning in a multitude of ways. Learning in diverse environments enhances students' communication, argumentation, and problem-solving skills. Diverse classrooms also contribute to students' emotional intelligence, improving empathy and perspective-taking in ways that prepare them to thrive personally and professionally. ${ }^{15}$ Learning among diverse peers and professors inculcates critical thinking abilities, prompting students to challenge their own received wisdom and culturally-bounded assumptions. Properly cultivated, diversity in the classroom expands students' interpretive capacity, showing how particular content can be approached from multiple angles. Diverse classrooms promote listening and expression, as students engage in critical analysis and teamwork across different communication styles. ${ }^{16} \mathrm{Stu}^{-}$ dent diversity also contributes to professional growth and satisfaction

${ }^{15}$ P. Christopher Earley and Soon Ang, Cultural Intelligence: Individual Interactions Across Cultures (Stanford: Stanford University Press, 2003).

${ }^{16}$ On the value of diversity for learning see Jiaxian Zhou and Kurt W. Fischer, "Culturally Appropriate Education: Insights From Educational Neuroscience," Mind, Brain, and Education 7, no. 4 (2013): 225-231; Milton J. Bennett, "Defining, Measuring, and Facilitating Intercultural Learning: A Conceptual Introduction to the Intercultural Education Double Supplement," Intercultural Education 20, no. S1-S2 (2009): 1-13; Susan Ambrose, Michael Bridges, Michele DiPietro, Marsha Lovett, and Marie Norman, How Learning Works: Seven Research-Based Principles for Smart Teaching (San Francisco: Wiley, 2010); Victor Savicki, ed., Developing Intercultural Competence and Transformation: Theory, Research and Application in International Education (Sterling: Stylus, 2008), 13-31; Margery Ginsberg and Raymond Wlodkowski, Diversity and Motivation: Culturally Responsive Teaching in College (New York: Wiley, 2009); Myron Lustig and Jolene Koester, Intercultural Competence: Interpersonal Communication Across Cultures, 8th ed. (Boston: Pearson, 2017); Scott Page, The Difference: How the Power of Diversity Creates Better Groups, Firms, Schools, and Societies (Princeton: Princeton University Press, 2007); Laura B. Perry and Leonie Southwell, "Developing Intercultural Understanding and Skills: Models and Approaches," Intercultural Education 22, no. 6 (2011): 453-466; Ruanni Tupas, "Intercultural Education in Everyday Practice," Intercultural Education 25, no. 4 (2014): 243-254. 
for faculty. Faculty enjoy opportunities to learn new things about the world, about teaching, and about their own areas of expertise by seeing it through their students' varied lenses. Teaching a diverse group of students keeps the teaching experience fresh and invigorating. Student diversity can ideally prompt faculty to develop new pedagogical approaches and think creatively about how to provide an excellent education to all students, across varied backgrounds. ${ }^{17}$

For these reasons, we should be enthusiastic about the diversity among our students and proactive in seizing opportunities to harness that diversity in pursuit of deeper learning for all.

The "for all" is important to emphasize. At the same time that diversity enhances learning, differences between the backgrounds and identities of faculty and students can pose barriers to learning. When students feel isolated and alienated in class, when they feel they do not belong, it impedes engagement and trust in the professor, which in turn diminishes learning. ${ }^{18}$ Students, especially those from minoritized groups, experience educational alienation from two common pathways: 1) when they are made to feel invisible and 2) when they are exoticized by their professors or their peers. ${ }^{19}$

${ }^{17}$ On the ways diversity enhance faculty teaching and experiences, see Bidisha Biswas and Shirin Deylami, "Finding Agency in the Margins: Lessons from Teaching as Immigrant Women of Color," PS: Political Science \& Politics 50, no. 4 (2017): 1011-1014; Stephen Brookfield, Becoming a Critically Reflective Teacher (New York: Wiley, 2017); Choy Siew Chee and Phaik Kin Cheah, "Teacher Perceptions of Critical Thinking Among Students and its Influence on Higher Education," International Journal of Teaching and Learning in Higher Education 20, no. 2 (2008): 198-206.

${ }^{18}$ On the relationship between belonging, learning, and academic success see Terrell L. Strayhorn, College Students' Sense of Belonging: A Key to Educational Success for All Students (New York: Routledge, 2012); Pyong-sik Yi, "Institutional Climate and Student Departure: A Multinomial Multilevel Modeling Approach," Review of Higher Education 31, no. 2 (2008): 161-183. See also Roderick Ferguson, The Reorder of Things: The University and Its Pedagogies of Minority Difference (Minneapolis: University of Minnesota Press, 2012); Diane Goodman, Promoting Diversity and Social Justice: Educating People from Privileged Groups (New York: Routledge, 2011); Mark Hearn, "Positionality, Intersectionality, and Power: Socially Locating the Higher Education Teacher in Multicultural Education," Multicultural Education Review 4, no. 2 (2012): 38-59.

${ }^{19}$ Isabel Moallem, "A Meta-Analysis of School Belonging and Academic Success and Persistence” (PhD diss., Loyola University Chicago, 2013), 726; Steven J. Spencer, Claude M. Steele, and Dianne M. Quinn, "Stereotype Threat and Women's Math Performance," Journal of Experimental Social Psychology 35, no. 1 (1999): 4-28; Joshua Aronson and 
Students can be made to feel invisible when teachers and peers overlook their identities, backgrounds, or learning needs. This happens, for example, when professors draw on illustrations and analogies from a very specific cultural context without self-awareness, or when textbooks always use the same gender pronouns to describe leadership positions, or when peers from more affluent families assume all students have experienced world travel. These actions, even when not intentional or malicious, can lead to feelings of exclusion that obstruct engagement and learning. The flip side of the coin is when students from minority or marginalized groups are exoticized and tokenized, perhaps being asked to represent their entire culture, region, or other identities. This can happen when professors expect minority students to educate the majority of the class about "their people." For example, when a professor turns to the one student from Vietnam and asks them to explain Southeast Asian culture, as if there was such a singular concept. Such attempts to bring student experience and diversity into the classroom are often well-intentioned, but can reinforce minoritized students' feelings of isolation.

The distinction between minority and minoritized helps to illustrate these points. ${ }^{20}$ The term "minority" in the education context is often

Michael Inzlicht, "The Ups and Downs of Attributional Ambiguity: Stereotype Vulnerability and the Academic Self-Knowledge of African-American students," Psychological Science 15, no. 12 (2004): 829-836; Joshua Aronson, Carrie B. Fried, and Catherine Good, "Reducing the Effects of Stereotype Threat on African American College Students By Shaping Theories of Intelligence," Journal of Experimental Social Psychology 38, no. 2 (2002): 113-125.

${ }^{20}$ For more on the use of minoritized as an illuminating concept in higher education studies, see: Michael Benitez, "Resituating Culture Centers Within a Social Justice Framework: Is There Room for Examining Whiteness?," in Culture Centers in Higher Education: Perspectives on Identity, Theory, and Practice, edited by Lori D. Patton (Sterling: Stylus, 2010), 119-134; Nana Osei-Kofi, Riyad A. Shahjahan, and Lori D. Patton, "Centering Social Justice in the Study of Higher Education: The Challenges and Possibilities for Institutional Change," Equity \& Excellence in Education 43, no. 3 (2010): 326-340; Sharon Lee, "Over-Represented and De-minoritized: The Racialization of Asian Americans in Higher Education," InterActions: UCLA Journal of Education and Information Studies 2, no. 2 (2006); Dafina-Lazarus Stewart, "Racially Minoritized Students at U.S. Four Year Institutions," The Journal of Negro Education 82, no. 2 (2013): 184197; Jodi L. Linley, "We Are (Not) All Bulldogs: Minoritized Peer Socialization Agents' Meaning-Making About Collegiate Contexts,"Journal of College Student Development 58, no. 5 (2017): 643-656; Koen Leurs and Sandra Ponzanesi, "Norms and Contestations: Ethnicized and Minoritized Students as Space Invaders in Dutch Higher Education," Etnofoor 25, no. 2 (2013): 73-97; Marlee M. Spafford, Vicki L. Nygaard, Fran Gregor, and Marcia A. Boyd, "Navigating the Different Spaces': Experiences of Inclusion 
used to describe groups whose members are few in number. For example, we might reference the Indonesian student minority at an Australian university or a Muslim minority at a majority-Hindu Indian college. In many cases, however, use of the term minority obscures the reality that many groups are numerically less represented at universities because they have been structurally excluded, or minoritized. In some cases these groups have faced historical and institutional barriers to higher education within their own country. A historically marginalized ethnic or religious group may make up a sizeable percentage of a country's population, but be a minority in university classrooms. Similarly, in many academic disciplines women are a numerical minority in the classroom, but certainly not in the population at large. In other cases, post-colonial and developmental asymmetries in educational opportunities across states lead students to travel abroad for university. To be a minority in an educational environment, then, sometimes reflects historical and social-structural forms of inequality at the international level.

In this sense, the term "minoritized" draws our attention to the forces of exclusion from higher education that make certain groups and individuals "minorities" in our universities and in our classrooms. This understanding, in turn, illuminates educators' responsibility for taking more proactive measures of inclusion.

Faculty have the power to serve as models for how to engage with and learn from diversity and intercultural exchange. Sometimes diversity in the classroom can give rise to misunderstandings and disagreements. Students will look to faculty for leadership - intellectual and ethical-in difficult and uncomfortable situations. Pejorative or offensive words in one country might not be taboo in another. Faculty may have to mediate conflict and intercultural friction among students. Faculty themselves may unintentionally offend their students. A faculty member's reaction or inaction in response to "hot moments" of intercultural misunderstanding

and Isolation among Racially Minoritized Faculty in Canada," The Canadian Journal of Higher Education 36, no. 1 (2006): 1-27. Minoritization and higher education have been written about extensively in the North American context but more recently also in Asian higher education contexts. Ngo Thi Hang Nga, "Access and Equity in Higher Education: A Case of Minority Students in Northwest Vietnam," Global Education Colloquium, April 3, 2019, https://drexel.edu/soe/resources/event-series/gec/April-3-2019-Event/; Vu Hoang Linh, Le Viet Thuy, and Giang Thanh Long, "Equity and Access to Tertiary Education: The Case of Vietnam" (Working Paper 10, Development and Policies Research Center [DEPOCEN], Vietnam, April 2010). 
and conflict is of paramount importance. Naming sources of inequality and correcting unintentionally ignorant or hurtful comments during class is especially important when faculty members hold privileged identities in their teaching context, either because they represent the dominant majority or a privileged minority identity. The more you know about your students and their educational context, the more likely you are to anticipate challenges that will arise and respond in productive ways that maximize student learning. ${ }^{21}$

Even faculty who are committed to creating supportive environments can inadvertently foster feelings of isolation and exclusion. For example, for most of us it is easier to learn students' names that are familiar, and we may struggle to differentiate Dave and Dan or Hee Yi and Li Yi if we are unfamiliar with those names. This understandable limitation becomes problematic when it leads faculty to disproportionately call on the students whose names they can pronounce, and avoid calling on those with names they are afraid of mispronouncing or confusing. To promote a feeling of belonging among students - to move from diversity to inclusion-faculty can take action to pronounce names correctly (e.g. using a pronunciation guide like http://hearnames.com/). These steps will give professors the confidence to call on students evenly, which invites all students equally into the learning environment.

This is but one example that illustrates how diversity on its own does not equal inclusion, and can even lead to feelings of exclusion. Having diversity in a classroom does not guarantee that students will listen to or learn from each other's different perspectives and strengths. In fact, the distinction between diversity and inclusion shows that faculty inaction can cause real harm. As Tienda explains, inclusion requires intentionality. It involves institutional and instructor-level "strategies and practices that promote meaningful social and academic interactions among students

${ }^{21}$ Sara Ahmed, On Being Included: Racism and Diversity in Institutional Life (Durham: Duke University Press, 2012); Alexander W. Astin, "Diversity and Multiculturalism on Campus: How Are Students Affected?," Change 25, no. 2 (2013): 44-49; Patricia Gurin, Eric Dey, Sylvia Hurtado, and Gerald Gurin, "Diversity and Higher Education: Theory and Impact on Educational Outcomes," Harvard Educational Review 72, no. 3 (2002): 330-367; Josipa Roska, Cindy Kilgo, Teniell Trolian, and Ernest Pascarella, "Engaging with Diversity: How Positive and Negative Experiences Shape Student's Cognitive Outcomes," The Journal of Higher Education 88, no. 3 (2017): 297-322. 
who differ in their experiences, views, and traits." 22 Inclusive pedagogy and curriculum promote access to learning and belonging for all. One could even conceive of inclusion as seeking to dismantle the privileging of certain differences or identities over others. ${ }^{23}$

In sum, for diversity to enhance learning for all, it needs to go handin-hand with deliberate and enthusiastic inclusion. ${ }^{24}$

\section{Overarching Goals and Chapter Overview}

At the same time that there is interest in diversity and inclusion, there is also faculty burnout and sometimes resistance. The demands on university faculty and administrators have shifted with time and expanded beyond being experts in a particular subject and discipline. Faculty in many institutions are increasingly expected to use novel pedagogies, create inclusive learning spaces, and facilitate positive intercultural interactions in their classes. Similarly, administrators are facing new pressures to be responsive to student voices and create inclusive curricula and campus communities. Being deliberately inclusive takes work, and not all educators have a clear sense of where to start or expand their efforts in this area. Indeed, many faculty members receive little to no pedagogical training in graduate school, let alone specific training in inclusive teaching and curricular leadership.

This book exists to showcase different ways of cultivating more inclusive classrooms and institutions across diverse contexts and identity groups. It will be valuable to many categories of faculty, administrators,

${ }^{22}$ Marta Tienda, "Diversity $\neq$ Inclusion: Promoting Integration in Higher Education," Educational Researcher 42, no. 9 (2013): 467. See also Rennie J. Moon, "Internationalisation Without Cultural Diversity? Higher Education in Korea," Comparative Education 52, no. l (2016): 91-108.

${ }^{23}$ Maurianne Adams, Lee Anne Bell, and Pat Griffin, eds., Teaching for Diversity and Social Justice, 2nd ed. (New York: Routledge, 2007); Asia McCleary-Gaddy, "Be Explicit: Defining the Difference Between the Office of Diversity \& Inclusion and the Office of Diversity \& Equity," Medical Teacher (2019): 1-2.

${ }^{24}$ Kimberly D. Tanner, "Structure Matters: Twenty-One Teaching Strategies to Promote Student Engagement and Cultivate Classroom Equity," CBE Life Sciences Education 12, no. 3 (2013): 322-331. On the importance of proactive engagement with different ideas for effective democratic deliberation, see Mary F. Scudder, "The Ideal of Uptake in Democratic Deliberation," Political Studies, no. 1962 (2019). 
education scholars, and those interested in education trends. We developed this book for educators who are new to Asia, for those who are familiar with their local context but experiencing demographic and curricular changes; and for those who are working in diverse settings outside of Asia as well. The book provides both broad frameworks and specific strategies to help faculty, administrators, students, and policy-makers make their own diverse higher education contexts more inclusive. The goal is not to paint all diversity-or all of Asian higher education-with one large brush. On the contrary, the goal here is to identify certain pedagogical, curricular, and institutional strategies that promote inclusivity across highly dissimilar contexts. ${ }^{25}$

It is for this reason that we have solicited a mix of contributions to this volume. As editors, we have tried to include diverse voices and analytic approaches, as well as give windows into different institutional and national contexts across Asia. Some chapters speak to specific populations of learners, including Confucian heritage learners, adults, women, and LGBTQ+ students. Some chapters emphasize inclusive pedagogical strategies that are relevant across Asia and the world-such as rubrics-while others are rooted in specific institutional and national contexts, including Singapore, Malaysia, Japan, and India. Many of the contributors to this volume hail from the country in which they are teaching or writing. Several authors, including the editors, do not. Some of the authors in this volume suggest that there are distinctive cultures within Asia that can influence the ways students react to different pedagogies. Other authors take less cultural approaches, focusing on economic or institutional forces that exert influence over learning and teaching in different Asian contexts. Other authors focus on the individual level, investigating the experience of individual students in specific educational contexts.

The book takes a holistic approach to the study of diversity and inclusion, looking at pedagogy, curriculum, and institutional design.

Part I emphasizes Pedagogy for Inclusion.

In Chapter 2, "Inclusive Pedagogy and Universal Design Approaches for Diverse Learning Environments" Catherine Sanger offers an overview

\footnotetext{
${ }^{25}$ Nguyen, Terlouw, and Pilot have noted the hubris and the deleterious effects of mapping pedagogical practices from one context onto another without attention to indigenous local pedagogies and effective practices. Mai Nguyen Phuong Mai, Cees Terlouw, and Albert Pilot, "Cooperative Learning in Vietnam and the West-East educational transfer," Asia Pacific Journal of Education 32, no. 2 (2012): 137-152.
} 
of two broad approaches to inclusive education before detailing a number of specific pedagogical strategies to promote learning across diverse contexts. This chapter will be especially relevant for those teaching outside their own cultural context, and/or teaching very diverse groups of students.

In Chapter 3, "Beyond Fairness and Consistency in Grading: The Role of Rubrics in Higher Education" Kiruthika Ragupathi and Adrian Lee introduce readers to an essential technique for inclusive assessment and provide very detailed information on why, when, and how to use rubrics. The chapter highlights the ways that rubrics enhance not only assessment but also improves student learning outcomes, teaching effectiveness, and course design.

Chapter 4, "Educating Adult Learners: Bridging Learners' Characteristics and the Learning Sciences" addresses a population of students that is increasingly important in the Asian higher education context. Authors Yan Yin Ho and Rebekah Lim Wei Ying describe how, as birth rates fall and the population ages, schools need to enroll adults to stay in business. Many Asian governments and education sectors are also focusing on re-skilling adults in response to rapid economic change and anticipated workforce needs for the Fourth Industrial Revolution. This chapter helps practitioners move past unfounded assumptions about what adult learners need to thrive, and offers evidence-based strategies for supporting adults in higher education.

Chapter 5, "Culture and Learning: Confucian Heritage Learners, Social-Oriented Achievement, and Innovative Pedagogies" argues that understanding students' cultural context can help faculty implement innovative pedagogies in ways that maximize student learning. Author Shelen Ho confronts the perception that certain pedagogies-specifically TeamBased Learning and Flipped Classrooms-are inappropriate in Asian contexts, demonstrating instead that sensitivity to local context can enhance the effectiveness of these techniques.

Part II, Liberal Arts Curricula in Asia Through the Diversity and Inclusion Lens, presents different case studies of how institutions have embedded diversity into curricula in different Asian liberal arts institutions.

In Chapter 6, "Diversifying the Liberal Arts Curriculum in an Asian Context," Charles Bailyn calls our attention to the absence of a serious engagement with Asian traditions and texts in the US liberal arts model. The author draws on personal experience designing a new curriculum for 
a Singapore-based liberal arts college, and how the strengths of a traditional liberal arts approach were enhanced by serious engagement with Asian content and sensitivity to local context.

In Chapter 7, "Service Learning as a Means to Understand SocioEconomic Privilege, Inequality, and Social Mobility," Mikiko Nishimura and Hitomi Yokote describe a multi-national service learning program hosted by a Japanese liberal arts university. The program was designed to promote not only greater awareness of diversity in socio-economic privilege but also to actively upend entrenched inequalities. The program brought together students from very different contexts within and beyond Asia to engage in significant intercultural and experiential learning.

In Chapter 8, "Inclusive Pedagogy and Writing Centres in Asian Higher Education," Kanika Singh shares her experience and lessons from directing the Centre for Writing and Communication at Ashoka University, India. The chapter highlights strategies for supporting learning as students are exposed to new pedagogies and asked to communicate across different dialects and languages.

Part III, Supporting Historically Marginalized Populations, includes two chapters.

Chapter 9, "Gender \& Sexual Diversity in Asian Universities" alerts readers to overt and subtler forms of discrimination and alienation experienced by LGBTQ+ students across many Asian higher education contexts. Authors Daryl WJ Yang and Khoo Hoon Eng identify a range of practices that enhance inclusion and present a typology for Asian universities in terms of their institutional approaches and levels of support toward LGBTQ students.

In Chapter 10, "Higher Education for Women in Asia," Solveig OlsonStrom and Nirmala Rao address historical and institutional forces that have led women to be under-served across many higher education contexts. Drawing on the experience of the Asian University for Women and other institutions, the authors describe empowering institutional and pedagogical strategies for counteracting historical forms of exclusion.

Lastly, in Part IV, Leadership for Inclusion, Nancy W. Gleason discusses "Strategic Leadership for Diversity and Inclusion in Higher Education," and how university and education leaders can help make diversity an institutional priority, creating broad stakeholder support for inclusive pedagogy and curricular design.

Our desire for this volume is that it will serve as a venue for exploring the diversity within Asia and across the world, not to suggest there 
is some sort of uniform Asian educational environment. We are mindful of Edward Said's much-quoted invocation that "Rather than the manufactured clash of civilizations, we need to concentrate on the slow working together of cultures that overlap, borrow from each other, and live together in far more interesting ways than any abridged or inauthentic mode of understanding can allow." 26 These processes are at work in diverse, collaborative higher education programs throughout Asia. We hope that each chapter instigates and contributes to existing conversations about how inclusive higher education can further develop across diverse contexts within Asia and beyond.

Acknowledgements It was very important to us as editors and educators that a volume on the topic of diversity and inclusion should be as widely available as possible to all readers, everywhere. We are therefore very happy to be offering this book Open Access, such that every chapter is available free of cost to all potential readers with Internet access. We are grateful to Yale-NUS College for sponsoring Open Access, and in particular the support of our Dean of Faculty Jeannette Ickovics and Vice President of Academic Affairs Joanne Roberts for facilitating this process. We want to thank Calvin Yeo Jing Xun who worked miracles under tight deadlines to format, reference-check, and copy-edit this entire volume and Lily Seah who provided administrative support for this project, without which it would not have come to fruition. For this particular chapter, my great thanks to Brandon Yoder, Laura Severin, and Shruti Tewari for edits, suggestions, and encouragement.

\section{BIBLIOGRAPHY}

Adams, Maurianne, Lee Anne Bell, and Pat Griffin, eds. Teaching for Diversity and Social Justice. 2nd ed. New York: Routledge, 2007.

Ahmed, Sara. On Being Included: Racism and Diversity in Institutional Life. Durham: Duke University Press, 2012.

Altbach, Philip G., and Maria Yudkevich. "Twenty-First Century Mobility: The Role of International Faculty." International Higher Education 90 (2017): $8-10$.

Ambrose, Susan, Michael Bridges, Michele DiPietro, Marsha Lovett, and Marie Norman. How Learning Works: Seven Research-Based Principles for Smart Teaching. San Francisco: Wiley, 2010.

${ }^{26}$ Edward W. Said, Orientalism (London: Penguin, 2003), xxii. 
Aronson, Joshua, and Michael Inzlicht. "The Ups and Downs of Attributional Ambiguity: Stereotype Vulnerability and the Academic Self-Knowledge of African-American students.” Psychological Science 15, no. 12 (2004): 829836.

Aronson, Joshua, Carrie B. Fried, and Catherine Good. "Reducing the Effects of Stereotype Threat on African American College Students by Shaping Theories of Intelligence." Journal of Experimental Social Psychology 38, no. 2 (2002): $113-125$.

Astin, Alexander W. "Diversity and Multiculturalism on Campus: How Are Students Affected?" Change 25, no. 2 (2013): 44-49.

Bekele, Teklu Abate. "Context in Comparative and International Education Studies." In Annual Review of Comparative and International Education 2017 (International Perspectives on Education and Society, Vol. 34), edited by A. Wiseman, 275-299. Bingley: Emerald Publishing Limited, 2018.

Benitez, Michael. "Resituating Culture Centers Within a Social Justice Framework: Is There Room for Examining Whiteness?" In Culture Centers in Higher Education: Perspectives on Identity, Theory, and Practice, edited by Lori D. Patton, 119-134. Sterling: Stylus, 2010.

Bennett, Milton J. "Defining, Measuring, and Facilitating Intercultural Learning: A Conceptual Introduction to the Intercultural Education Double Supplement." Intercultural Education 20, no. S1-S2 (2009): 1-13.

Bhandari, Rajika, and Alessia Lefébure, eds. Asia: The Next Higher Education Superpower? New York: Institute of International Education, 2015.

Biswas, Bidisha, and Shirin Deylami. "Finding Agency in the Margins: Lessons from Teaching as Immigrant Women of Color.” PS: Political Science \& Politics 50, no. 4 (2017): 1011-1014.

Brookfield, Stephen. Becoming a Critically Reflective Teacher. New York: Wiley, 2017.

Castro, Paloma, Jane Woodin, Ulla Lundgren, and Michael Byram. "Student Mobility and Internationalisation in Higher Education: Perspectives from Practitioners." Language and Intercultural Communication 16, no. 3 (2016): $418-436$.

Chan, Sheng-Ju. "Shifting Patterns of Student Mobility in Asia." Higher Education Policy 25, no. 2 (2012): 207-224.

Chee, Choy Siew, Daljeet Singh, Yow Lin Liew, Mun Yee Lee, Audrey Malenee, and Norkhadirah Anuar. "Influence of Culture on Students' Awareness of How and Why They Learn." Malaysian Journal of Learning and Instruction 12 (2015): 49-67.

Choudaha, Rahul. "Three Waves of International Student Mobility (19992020)." Studies in Higher Education 42, no. 5 (2017): 825-832.

Choy, Siew Chee, and Phaik Kin Cheah. "Teacher Perceptions of Critical Thinking Among Students and Its Influence on Higher Education." International 
Journal of Teaching and Learning in Higher Education 20, no. 2 (2008): 198-206.

Collins, C. M. Lee, J. Hawkins, and D. Neubauer, eds. The Palgrave Handbook of Asia Pacific Higher Education. New York: Palgrave Macmillan, 2016.

Earley, P. Christopher, and Soon Ang. Cultural Intelligence: Individual Interactions Across Cultures. Stanford: Stanford University Press, 2003.

Ferguson, Roderick. The Reorder of Things: The University and Its Pedagogies of Minority Difference. Minneapolis: University of Minnesota Press, 2012.

Gertz, Sun Hee Kim, Betsy Huang, and Lauren Cyr, eds. Diversity and Inclusion in Higher Education and Societal Contexts: International and Interdisciplinary Approaches. New York: Palgrave Macmillan, 2018.

Ginsberg, Margery, and Raymond Wlodkowski. Diversity and Motivation: Culturally Responsive Teaching in College. New York: Wiley, 2009.

Gleason, Nancy W., ed. Higher Education in the Era of the Fourth Industrial Revolution. Singapore: Palgrave Macmillan, 2018.

Goodman, Diane. Promoting Diversity and Social Justice: Educating People from Privileged Groups. New York: Routledge, 2011.

Gurin, Patricia, Eric Dey, Sylvia Hurtado, and Gerald Gurin. "Diversity and Higher Education: Theory and Impact on Educational Outcomes." Harvard Educational Review 72, no. 3 (2002): 330-367.

Hearn, Mark. "Positionality, Intersectionality, and Power: Socially Locating the Higher Education Teacher in Multicultural Education." Multicultural Education Review 4, no. 2 (2012): 38-59.

Heyward, Mark. "From International to Intercultural: Redefining the International School for a Globalized World." Journal of Research in International Education 1, no. 1 (2002): 9-32.

Hiller, Gundula G., and Maja Wozniak. "Developing an Intercultural Competence Programme at an International Cross-Border University." Intercultural Education 20, no. 4 (2009): 113-124.

Horie, Miki. "Internationalization of Japanese Universities: Learning from the CAMPUS Asia Experience.” International Higher Education 78 (2014): 1921.

Huang, Futao. "International Faculty at Japanese Universities: Their Demographic Characteristics and Work Roles." Asia Pacific Education Review 19, no. 2 (2018): 263-272.

Huang, Futao, Martin J. Finkelstein, and Michele Rostan, eds. The Internationalization of the Academy: Changes, Realities and Prospects. Dordrecht: Springer, 2014.

Kamenopoulou, Leda, ed. Inclusive Education and Disability in the Global South. New York: Palgrave, 2018. 
Kell, Peter, and Gillian Vogl, eds. Global Student Mobility in the Asia Pacific: Mobility, Migration, Security and Wellbeing of International Students. Cambridge: Cambridge Scholars Publishing, 2010.

Kember, David. "Misconceptions About the Learning Approaches, Motivation and Study Practices of Asian Students." Higher Education 40, no. 1 (2000): 99-121.

- "International Students from Asia." In The Routledge International Handbook of Higher Education, edited by Malcom Tight, Ka Ho Mok, Jeroen Huisman, and Christopher Morphew, 47-60. Florence: Routledge, 2009.

-. "Why Do Chinese Students Out-Perform Those from the West? Do Approaches to Learning Contribute to the Explanation?" Cogent Education 3, no. 1 (2016): 1248187.

Kim, Stephanie K. "Western Faculty 'Flight Risk' at a Korean University and the Complexities of Internationalisation in Asian Higher Education." Comparative Education 52, no. 1 (2016): 78-90.

Kim, Terri. "Shifting Patterns of Transnational Academic Mobility: A Comparative and Historical Approach." Comparative Study 45, no. 3 (2009): 387403.

Lau, Ken, and Chia-Yen Lin. "Internationalization of Higher Education and Language Policy: The Case of a Bilingual University in Taiwan." Higher Education 74, no. 3 (2017): 437-454.

Lee, Jenny, Jae-Eun Jon, and Kiyong Byun. "Neo-Racism and Neo-Nationalism Within East Asia: The Experiences of International Students in South Korea." Journal of Studies in International Education 21, no. 2 (2017): 136-155.

Lee, Sharon. "Over-Represented and De-minoritized: The Racialization of Asian Americans in Higher Education." InterActions: UCLA Journal of Education and Information Studies 2, no. 2 (2006).

Leung, Doris Y. P., Paul Ginns, and David Kember. "Examining the Cultural Specificity of Approaches to Learning in Universities in Hong Kong and Sydney." Journal of Cross-Cultural Psychology 39, no. 3 (2008): 251-266.

Leurs, Koen, and Sandra Ponzanesi. "Norms and Contestations: Ethnicized and Minoritized Students as Space Invaders in Dutch Higher Education." Etnofoor 25, no. 2 (2013): 73-97.

Linley, Jodi L. "We Are (Not) All Bulldogs: Minoritized Peer Socialization Agents' Meaning-Making About Collegiate Contexts." Journal of College Student Development 58, no. 5 (2017) 643-656.

Lustig, Myron, and Jolene Koester. Intercultural Competence: Interpersonal Communication Across Cultures. 8th ed. Boston: Pearson, 2017.

McCleary-Gaddy, Asia. "Be Explicit: Defining the Difference Between the Office of Diversity \& Inclusion and the Office of Diversity \& Equity." Medical Teacher (2019): 1-2. 
Moallem, Isabel. "A Meta-Analysis of School Belonging and Academic Success and Persistence." PhD diss., Loyola University Chicago, 2013.

Moon, Rennie J. "Internationalisation Without Cultural Diversity? Higher Education in Korea." Comparative Education 52, no. 1 (2016): 91-108.

Morley, Louise, Nafsika Alexiadou, Stela Garaz, José González-Monteagudo, and Marius Taba. "Internationalisation and Migrant Academics: The Hidden Narratives of Mobility." Higher Education 76, no. 3 (2018): 537-554.

Ngo, Thi Hang Nga. "Access and Equity in Higher Education: A Case of Minority Students in Northwest Vietnam." Global Education Colloquium, April 3, 2019. https://drexel.edu/soe/resources/event-series/gec/April-3-2019Event/.

Nguyen, Mai Phuong Mai, Cees Terlouw, and Albert Pilot. "Cooperative Learning in Vietnam and the West-East educational transfer." Asia Pacific Journal of Education 32, no. 2 (2012): 137-152.

Niles, F. Sushila. "Cultural Differences in Learning Motivation and Learning Strategies: A Comparison of Overseas and Australian Students at an Australian University." International Journal of Intercultural Relations 19, no. 3 (1995): 369-385.

Osei-Kofi, Nana, Riyad A. Shahjahan, and Lori D. Patton. "Centering Social Justice in the Study of Higher Education: The Challenges and Possibilities for Institutional Change." Equity \& Excellence in Education 43, no. 3 (2010): 326-340.

Page, Scott. The Difference: How the Power of Diversity Creates Better Groups, Firms, Schools, and Societies. Princeton: Princeton University Press, 2007.

Perry, Laura B., and Leonie Southwell. "Developing Intercultural Understanding and Skills: Models and Approaches." Intercultural Education 22, no. 6 (2011): 453-466.

Qi, Wu. "Re-examining the 'Chinese learner': A Case Study of Mainland Chinese Students' Learning Experiences at British Universities.” Higher Education 70, no. 4 (2015): 753-766.

Ramburuth, Prem, and John McCormick. "Learning Diversity in Higher Education: A Comparative Study of Asian International and Australian Students." Higher Education 42, no. 3 (2001): 333-350.

Ratanawijitrasin, Sauwakon. "The Evolving Landscape of South-East Asian Higher Education and the Challenges of Governance." In The European Higher Education Area, edited by Adrian Curaj, Liviu Matei, Remus Pricopie, Jamil Salmi, and Peter Scott, 221-238. New York: Springer, 2015.

Roser, Max, and Esteban Ortiz-Ospina. "Tertiary Education." https:// ourworldindata.org/tertiary-education. 
Roska, Josipa, Cindy Kilgo, Teniell Trolian, and Ernest Pascarella. "Engaging with Diversity: How Positive and Negative Experiences Shape Student's Cognitive Outcomes." The Journal of Higher Education 88, no. 3 (2017): 297322 .

Sadler-Smith, E., and F. Tsang. "A Comparative Study of Approaches to Studying in Hong Kong and the United Kingdom." British Journal of Educational Psychology 68, no. 1 (1998): 81-93.

Said, Edward W. Orientalism. London: Penguin, 2003.

Sakurai, Yusuke, Anna Parpala, Kirsi Pyhältö, and Sari Lindblom-Ylänne. "Engagement in Learning: A Comparison Between Asian and European International University Students." Compare: A Journal of Comparative and International Education 46, no. 1 (2016): 24-47.

Sakurai, Yusuke, Kirsi Pyhältö, and Sari Lindblom-Ylänne. “Are Chinese University Students More Likely to Exhibit a Surface Approach to Learning Than Other International Students in Finland?" Journal of Research in International Education 13, no. 2 (2014): 135-148.

Savicki, Victor, ed. Developing Intercultural Competence and Transformation: Theory, Research and Application in International Education. Sterling: Stylus, 2008.

Scudder, Mary F. “The Ideal of Uptake in Democratic Deliberation." Political Studies, no. 1962 (2019).

Shin, Gi-Wook, Oh Yeon-Cheon, and Rennie J. Moon, eds. Internationalizing Higher Education in Korea: Challenges and Opportunities in Comparative Perspective. New York: Brookings Institution Press, 2016.

Smith, Swee Noi. "Approaches to Study of Three Chinese National Groups." British Journal of Educational Psychology 71, no. 3 (2001): 429-441.

Spafford, Marlee M., Vicki L. Nygaard, Fran Gregor, and Marcia A. Boyd. "Navigating the Different Spaces': Experiences of Inclusion and Isolation Among Racially Minoritized Faculty in Canada." The Canadian Journal of Higher Education 36, no. 1 (2006): 1-27.

Spencer, Steven J., Claude M. Steele, and Dianne M. Quinn. "Stereotype Threat and Women's Math Performance." Journal of Experimental Social Psychology 35, no. 1 (1999): 4-28.

Stewart, Dafina-Lazarus. "Racially Minoritized Students at U.S. Four Year Institutions." The Journal of Negro Education 82, no. 2 (2013): 184-197.

Strayhorn, Terrell L. College Students' Sense of Belonging: A Key to Educational Success for All Students. New York: Routledge, 2012.

Sun, Haoda, and John E. Richardson. "Perceptions of Quality and Approaches to Studying in Higher Education: A Comparative Study of Chinese and British Postgraduate Students at Six British Business Schools." Higher Education 63, no. 3 (2012): 299-316. 
Tang, T. Heng. "Different is Not Deficient: Contradicting Stereotypes of Chinese International Students in US Higher education." Studies in Higher Education 43, no. 1 (2018): 22-36.

Tanner, Kimberly D. "Structure Matters: Twenty-One Teaching Strategies to Promote Student Engagement and Cultivate Classroom Equity." CBE Life Sciences Education 12, no. 3 (2013): 322-331.

Thu, T. Do, and Duy N. Pham. "Challenges of Student Mobility in Southeast Asia.” International Higher Education, no. 84 (2016): 24-26.

Tienda, Marta. "Diversity $\neq$ Inclusion: Promoting Integration in Higher Education." Educational Researcher 42, no. 9 (2013): 467.

Tupas, Ruanni. "Intercultural Education in Everyday Practice." Intercultural Education 25, no. 4 (2014): 243-254.

Ullah, AKM Ahsan, and Muhammad Azizuddin. "South Asian Student Migration to Nordic Countries: Changing Initial Motivations." Asian Profile 46, no. 1 (2018).

$\mathrm{Vu}$, Hoang Linh, Le Viet Thuy, and Giang Thanh Long. "Equity and Access to Tertiary Education: The Case of Vietnam.” Working Paper 10, Development and Policies Research Center (DEPOCEN), Vietnam, April 2010.

Watkins, Megan, Christina Ho, Rose Butler. "Asian Migration and Education Cultures in the Anglo-Sphere." Journal of Ethnic and Migration Studies 43, no. 14 (2017): 2283-2299.

Wen, Die, and Jie Hao Hu. "International Students' Experiences in China: Does the Planned Reverse Mobility Work?" International Journal of Educational Development 61 (2018): 204-212.

Wong, Joseph Kee-Kuok. "Are the Learning Styles of Asian International Students Culturally or Contextually Based?" International Education Journal 4, no. 4 (2004): 154-166.

$\mathrm{Xu}$, Cora Lingling. "Identity and Cross-Border Student Mobility: The Mainland China-Hong Kong Experience." European Educational Research Journal 14, no. 1 (2015): 65-73.

Yang, Chunyan, and Li Ba. "The Use of Metacognitive Strategies by Chinese Phd Students of Social Sciences in Australian Universities." International Journal of Educational Research 97 (2019): 43-52.

Yang, Peidong. "Compromise and Complicity in International Student Mobility: The Ethnographic Case of Indian Medical Students at a Chinese University." Discourse: Studies in the Cultural Politics of Education 39, no. 5 (2018): 694708.

Yi, Pyong-sik. "Institutional Climate and Student Departure: A Multinomial Multilevel Modeling Approach." Review of Higher Education 31, no. 2 (2008): 161-183.

Yonezawa, Akiyoshi, Hugo Horta, and Aki Osawa. "Mobility, Formation and Development of the Academic Profession in Science, Technology, Engineering 
and Mathematics in East and South East Asia." Comparative Education 52, no. 1 (2016): 44-61.

Yudkevich, Maria, Philip G. Altbach, and Laura E. Rumbley, eds. International Faculty in Higher Education: Comparative Perspectives on Recruitment, Integration, and Impact. New York: Routledge, 2017.

Zhou, Jiaxian, and Kurt W. Fischer. "Culturally Appropriate Education: Insights From Educational Neuroscience." Mind, Brain, and Education 7, no. 4 (2013): 225-231.

Zhu, Chang, Martin Valcke, and Tammy Schellens. "A Cross-Cultural Study of Chinese and Flemish University Students: Do They Differ in Learning Conceptions and Approaches to Learning?" Learning and Individual Differences 18 , no. 1 (2008): 120-127.

Open Access This chapter is licensed under the terms of the Creative Commons Attribution 4.0 International License (http://creativecommons.org/licenses/ by $/ 4.0 /$ ), which permits use, sharing, adaptation, distribution and reproduction in any medium or format, as long as you give appropriate credit to the original author(s) and the source, provide a link to the Creative Commons license and indicate if changes were made.

The images or other third party material in this chapter are included in the chapter's Creative Commons license, unless indicated otherwise in a credit line to the material. If material is not included in the chapter's Creative Commons license and your intended use is not permitted by statutory regulation or exceeds the permitted use, you will need to obtain permission directly from the copyright holder.

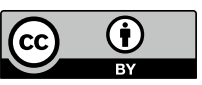

